\begin{tabular}{|c|c|c|}
\hline $4 .+6$ & $\begin{array}{l}\text { European Association for the } \\
\text { Development of Renewable Energies, Environment } \\
\text { and Power Quality (EA4EPQ) }\end{array}$ & $\begin{array}{l}\text { International Conference on Renewable Energies and Power Quality } \\
\text { (ICREPQ'12) } \\
\text { Santiago de Compostela (Spain), 28th to 30th March, } 2012\end{array}$ \\
\hline
\end{tabular}

\title{
VERCampus - Live Park of Renewable Energies
}

\author{
Vicente Leite $^{1}$ José Batista $^{2}$ and Orlando Rodrigues ${ }^{3}$ \\ Polytechnic Institute of Bragança \\ Campus Santa Apolónia, apartado 1038, 5301-854 Bragança, Portugal \\ ${ }^{1}$ avtl@ipb.pt, ${ }^{2}$ jbatista@ipb.pt, ${ }^{3}$ orlando@ipb.pt
}

\begin{abstract}
This paper presents the VERCampus Project - Live Campus of Renewable Energies - which integrates a set of technologies, infrastructures, and initiatives carried out in the Campus of the Polytechnic Institute of Bragança (IPB) regarding the renewable energies technologies and distributed power generation systems promotion and dissemination for IPB students and for other schools and education levels, stakeholders and all community in general. The aim is to create an attractive and innovative green Campus as a real platform for training, education and dissemination activities in order to understand the real cost of the energy and stimulate better behaviours in view of a rational use of energy. The results consist of an experimental framework based on commercial equipment with new and innovative functionalities developed by students and teaching staff of IPB in view of studies and transfer of practical information and technology for the community. This paper describes the main activities achieved for these purposes and some details are presented.
\end{abstract}

\section{Key words}

Photovoltaic Energy, Wind Energy, Hydro Energy, Biodiesel, Electric Vehicles, Microgrids.

\section{Introduction}

The consumption of electrical energy is growing and, at the same time, the number of systems based on electricity will increase in the next decades. It is expect that more than $60 \%$ of all energy consumption will be converted and used as electricity [1]. Furthermore, emerging climate changes as well as continuous social and political instability in many countries which produce the conventional energy based on fossil fuels argue to find future solutions as more sustainable as possible. Thus, it is mandatory to change from conventional to renewable energy sources and a wide-spread of these renewable sources in distribution networks is increasing strongly. Consequently, the power systems are changing rapidly as a large number of dispersed generation units, integrating renewable and non-renewable sources such as wind turbines (WT), photovoltaic (PV) systems, small hydro turbines, fuel cells and gas/steam powered combined heat and power stations are being installed all over the World [1], [2]. As the new technology is becoming more and more available at reasonable prices, and the installation of small systems is booming such as home solar and wind systems, the benefits and the challenges must be widely spread. If, on the one hand, the efficiency of the technology used in power generation, transmission/ distribution and end-user equipment has to be continuously improved and correctly sized for every application, on the other hand, it is urgent to encourage more efficient behaviour of everyone in view of a more rational and efficient use of energy.

Since the mid of 2007 the Polytechnic Institute of Bragança (IPB) is developing an innovative project named VERCampus aimed the implementation of a "live park" of renewable energies in its university Campus dedicated to the dissemination of their technologies as well as to a rational use of energy, not only electrical but also all other forms of energy. Since then, under this project, IPB has already carried out activities and several initiatives to improve energy efficiency of some buildings and has integrated renewable energy systems (solar thermal, photovoltaic, wind, small hydro, biofuels, and electric vehicles).

This paper presents the main features of the VERCampus Project, the implemented infrastructures and their diversity, the goals, and the achieved results.

\section{The Main Infrastructures}

The VERCampus Project includes a broad and diverse set of infrastructures and technologies used in the efficient conversion of the electric energy from the renewable sources such as photovoltaic, wind and hydro.

At this stage it has already been installed:

- 3 PV systems with a total power of $45 \mathrm{~kW}(15 \mathrm{~kW}$ in each of the schools of the IPB Campus);

- 2 WTs with a total output power of $7.4 \mathrm{kWp}$;

- Several thermodynamic solar systems to produce domestic hot water (DHW) of several bars, canteen, and three residences of students in the IPB Campus;

- A $2 \mathrm{~kW}$ hydro power plant by taking advantage of the river Fervença that crosses the IPB Campus;

- Two electric vehicles;

- A hybrid system (wind and photovoltaic) to small isolated systems;

- A glass facade with PV glass in the library of the School of Technology with a peak power $1.3 \mathrm{~kW}$;

- A solar tracker with a $3 \mathrm{kWp} \mathrm{PV}$ panel;

- A $1.4 \mathrm{kWp}$ wind turbine;

- A $5 \mathrm{~kW}$ smart microgrid;

- A production unit of biodiesel from used cooking oil and a $5 \mathrm{~kW}$ biodiesel generator;

- An integrated monitoring system. 
The solar tracker, the PV glass facade, the $1.3 \mathrm{~kW}$ WT, the biodiesel generator and a bank of solar batteries are integrated into a $5 \mathrm{~kW}$ microgrid for isolated and selfsustainable systems. This smart grid uses the latest technology with innovative and modularity features that allows its expansion to a condominium or even a small isolated village being an effective solution that can be used wherever electrical energy is necessary since there are still 1.4 billion people in the World that, unfortunately, do not have access to electrical energy [3].

VERCampus was thought and designed as a park to be open to the community through a series of activities ranging from education and long life learning to the projects of technology transfer and $\mathrm{R} \& \mathrm{D}$, through the dissemination of renewable energy and technologies involved, with the surrounding community, particularly businesses, public and private institutions and schools of different levels of education beyond the IPB students. The designation of "live park" is intended to emphasize that it is permanently active, through a regular set of activities open to the community in general.

\section{Description of the Main Activities}

The next sections describe, in some detail, the main activities achieved under the Project VERCampus.

\section{A. Photovoltaic Systems}

For the integration of PV energy in the IPB Campus it was adopted a set of three PV systems, distributed by the three schools of the main Campus of IPB in order to consume all the energy produced at every moment. It was adopted a modular configuration, which is a characteristic of PV systems, comprised of three units, each one with an output power of $5 \mathrm{~kW}$, in order to inject all the produced energy into the grid, in a balanced way, through the three phases of three-phase power system of each school as illustrated in Fig. 1 (left). Each PV system consists of:

- 28 PV modules (GEPVP-205-M from GE Energy) which account for a peak power of $17.22 \mathrm{kWp}$, forming a matrix, consisting of two parallel strings, as shown in Fig. 1 (left);

- A PV inverter (SMC 5000A from SMA) for the connection to the grid.

In order to perform guided visits it was assured simple and safe access to the PV installations on the roof.

Equipment for remote monitoring was installed in each school in order to measure the solar radiation and a wide range of electrical measurements, as for instance, the daily and total produced energy, the instantaneous power, the history of faults. More details are presented in section $L$.

IPB will provide updated information about the performance and production results of the PV systems, for

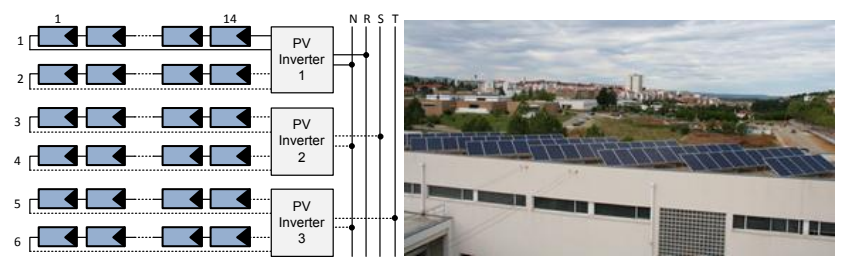

Fig. 1. Configuration of one PV system (left) and a partial photo of the PV panel (right). all the community, through the website of the VERCampus Project. As an example, it can be referred that the energy produced by the nine PV systems since their commissioning in June 10 of 2010 until December 31 of 2011 was $119.98 \mathrm{MWh}$. In 2011, the total energy yield from these PV systems was $77.74 \mathrm{MWh}$. This practical information is very important for many small investors to evaluate future investments. The website will also provide practical and very important information, for installers and owners, like the problems and solutions related to the PV systems of the School of Agriculture where the inverters were going out of service very frequently, in the beginning, because of high values of the internal electrical grid.

\section{B. Wind Turbines}

The IPB has installed wind energy in the former silos, used to storage cereals and shown in Fig. 2, which is now an IPB building, with about $50 \mathrm{~m}$ high, near the center of the city and very close to the IPB Campus.

In the context of the VERCampus Project it must be emphasized the possibility of safely guided visits once the turbines are accessible via interior stairs (about 250 steps). The solution used to fix the turbines on the roof is also an issue of interest.

The grid connection was made under the Portuguese significant policy initiative called microgeneration that was started in Portugal in 2007 with a premium feed-in tariff of $0.65 € / \mathrm{kWh}$ [4]. This feed-in tariff is now $0.4 € / \mathrm{kWh}$ for the solar PV systems and $70 \%$ of this value for wind systems. For this subsidized feed-in tariff there is a limit of $3.68 \mathrm{~kW}$ for the power connected to the grid for each system owner. Thus, two wind turbines Montana from FORTIS have been installed and connected to the grid with the single phase inverter WB 3800 with a rated output power of $3.8 \mathrm{~kW}$. Each WT uses a $5 \mathrm{kWp}$ permanent magnet synchronous generators. Equipment for remote monitoring was jointly installed with the turbines to measure the wind speed and a wide range of electrical measurements as for the PV systems. Since there is lack of information about the potential of this kind of small-scale WTs in urban areas, by using this monitoring system, the IPB will provide updated information for all the community through the website of the VERCampus Project. As an example it can be referred that the energy produced by the two wind turbines since their commissioning in May 18 until December 31 of 2011 was $1,956 \mathrm{kWh}$.

\section{Thermodynamic Solar Systems}

IPB has also installed thermodynamic solar systems for DHW heating in all bars, university canteen and three
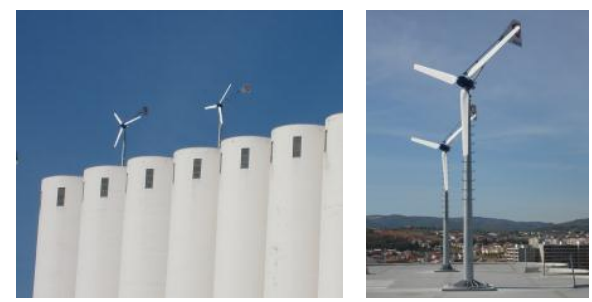

Fig. 2. Wind turbines on the roof of the former silos. 
residences of students. These systems were integrated with the existing solutions and they make a pre-heating of water in order to reduce the consumption of natural gas. Unfortunately, there are not separate meters for the gas consumption used for heating DHW and, on the other hand, the gas consumption for heating DHW is a small part of the consumption needed by the central heating. Thus, there is no possibility of making a reliable comparative study of the natural gas consumption, before and after the installation of these systems. However, based on the studies carried out there is the expectation of saving gas in the heating of DHW up to $30 \%$.

\section{Hydro Power Plant}

Taking advantage of an irrigation canal available in the Campus, shown in Fig. 3, the IPB, as in [5], has built a pico hydro power plant for electricity generation and demonstration of specific solutions and technologies used in very small hydroelectric power generation as in [5]-[7]. In order not to interfere in the riverbed and to maintain the landscape context, the renewable source of energy is a water canal usually used for irrigation. The water is taken from the river Fervença, which crosses the IPB Campus, by diverting it through an intake at a small weir.

The pico hydro power plant was built in a place of passage of students and people in general since the IPB has an open Campus. The aim is to be an open platform for dissemination and demonstration of hydro energy, both for regular guided visits as for people that are passing by. In this place, as in the whole length of the river Fervença in IPB Campus, the water level varies significantly every year, at the time of heaviest rains. To prevent that the rise of the level of the river could flood the generator and other equipment a specific solution was tailored according to the geography in the site from civil works through to turbine design. Thus, unlike the usual, two water turbines were mounted at the top of a draft tube and not downstream.

A small power house, shown in Fig. 4, was designed and built for the two specific turbines and with the purpose of being an experimental platform for studies and visits. This small hydroelectric central has stairs to go down to the
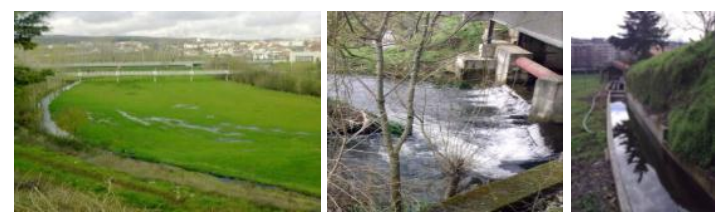

Fig. 3. Irrigation canal in the IPB Campus (left), small intake weir in the river Fervença (center), and the end of canal (right).

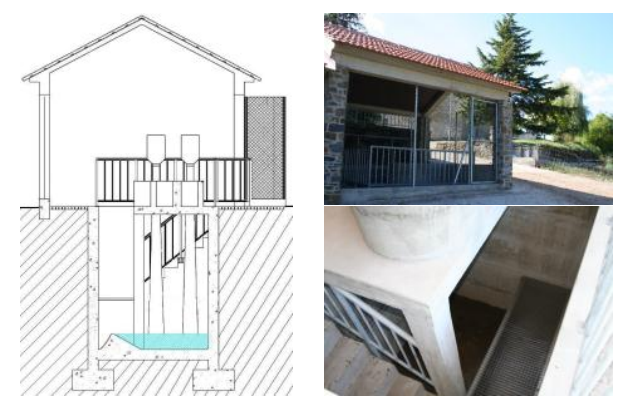

Fig. 4. Cross-section and perspective photos of the pico hydro power house. gallery and a platform for viewing the draft tube, the basin of discharge and the intake of the drainage tube that returns the water again to river.

Two water canals were built ending in a form of "snail" where the two water turbines were mounted as shown in Fig. 5. It was built a third canal to return the excess of water to the original irrigation canal. The turbines were placed upstream of the draft tube of water to prevent flooding due to rises in the level of the river which can rise more than 2 meters high in the site.

A $1 \mathrm{~kW}$ water turbine was mounted in the center of each "snail" operating on low heads since the turbines have a low head propeller design. In this case the head is $2.5 \mathrm{~m}$. The water turns the propeller, creating shaft power which in turn powers the generator producing electricity. This kind of solution can be ideally suited for a wide range of sites in order to produce electric energy from small water resources and heads. In this case it is not expected the operation of the pico hydro in the summer months. When the water flow is high enough, the turbine of the water canal at the right side starts working (see Fig. 5). When the flow is stronger, the water overflows from the right canal to the canal in the center, putting into operation the second turbine. If for some reason the water is excessive, the excess of water overflows into a third canal and returns to the original irrigation canal. Thus, with the installation of two turbines of lesser power $(1 \mathrm{~kW})$ instead of one of $2 \mathrm{~kW}$, it is possible, on the one hand, to extend for more months the energy production and, on the other hand, with the second turbine, take advantage of the highest water flow in the rainiest months. Despite the low power, these very small hydro plants have attracted great interest [5]-[7] and should not be neglected since the energy is the product of the power multiplied by time. Therefore, time is energy and the water turbines operate 24 hours a day. Just one of these turbines, operating only 9 months a year produce approximately the same energy of a $3 \mathrm{~kW}$ PV system mounted on a roof in Bragança.

\section{E. Electric Vehicles}

Sustainable mobility is an urgent requirement in the near future. Battery electric vehicles play an important role for this goal. The typical electric propulsion system consists of one or more batteries, an electric motor and an electronic controller that converts the energy from the batteries (DC) in a form suitable for power control of the electric motor (AC voltage with variable amplitude and frequency).

In the VERCampus Project two electric vehicles are being developed: the ECO Buggie IPB and the ECO solar IPB, which are shown in Fig. 6. This aims to demonstrate the technology of electric vehicles and the feasibility of their use for the overall energy efficiency and $\mathrm{CO}_{2}$
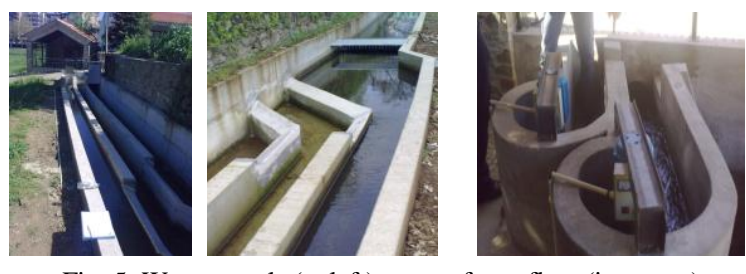

Fig. 5. Water canals (at left), zone of overflow (in center) and turbines in the "snails" (at right). 


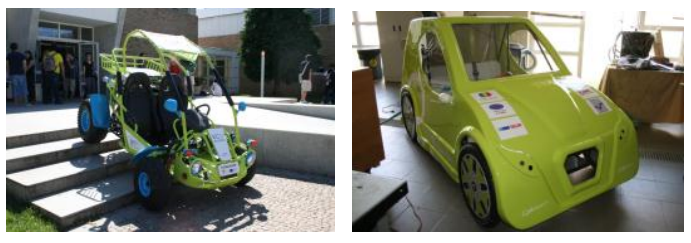

Fig. 6. ECO Buggie IPB (left) and ECO solar IPB (right).
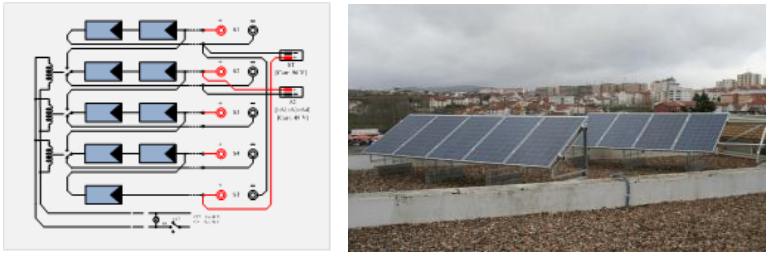

Fig. 7. PV panel (right) for solar chargers with terminals available for different PV configurations (left).

reduction. Also the integration with the microgrid described in section $K$ is a future issue to be developed. In both cases the batteries are charged with a $2 \mathrm{~kW} \mathrm{PV} \mathrm{panel,}$ shown in Fig. 7, and two solar chargers.

The electric propulsion systems are based on innovative technology and use an axial flux permanent magnet synchronous motor of $13 \mathrm{~kW}$ in the ECO Buggie IPB and $2.3 \mathrm{~kW}$ in the ECO Solar IPB. A lithium battery was produced by order for the first in order to reduce weight and maximize the capacity for the available volume. The cost of the battery is about $50 \%$ of the cost of the vehicle

\section{F. Hybrid system}

For demonstration purposes of autonomous systems widely used in low power applications it was installed a hybrid system combining two renewable energy sources: a PV module and a small WT. The simultaneous use of more than one renewable source makes possible to produce the energy more distributed over time. This prevents the accumulation of power in larger quantities, which reduces the capacity of batteries. This is especially true when the renewable sources are quite complementary. For example, a small WT can produce during the winter, the energy that a PV panel cannot but, on the other hand, this PV panel will produce in the summer, the energy that may not be generated by the WT. This system is shown in Fig. 8 and uses a combination of solar photovoltaic and wind energy to charge two $12 \mathrm{~V}$ batteries which, in turn, through a voltage inverter for isolated systems, feed a small lighting circuit. The charge controller is also used, whenever necessary, to charge the batteries of an electric scooter.

A LabVIEW application was developed and several functionalities have been implemented in order to monitor and record data from this hybrid system. The graphical user interface consists of four menus: Hybrid System, Total Harmonic Distortion (THD), Inverter and System Setup. The first two are shown in Fig. 9. The main physical and electrical signals monitored are the following:

- Current of PV module and wind generator;

- Battery voltage and DC power input;

- Current of DC loads;

- Voltage and current of AC loads;

- Power factor and harmonic distortion;

- Type of connected AC loads (RLC);
- AC powers (W, VA and VAr);

- THD for voltage and current;

- Wind speed $(\mathrm{m} / \mathrm{s})$ and outdoor temperature $\left({ }^{\circ} \mathrm{C}\right)$;

- Lighting level (Lux).

\section{G. Photovoltaic Glass Facade}

The building integration of PV energy is one of the applications of the PV systems with high development potential. In the context of the VERCampus, and for demonstration purposes, 29 of the existing glass of the glass facade of the library of School of Technology and Management were replaced by photovoltaic glass.

The PV glass were made by order, with the exact dimensions of the existing frames, and they consist of conventional double glass with photovoltaic cells mounted inside under vacuum, with connection terminals to the outside. Each one of the PV glass is composed by a set of $24 \mathrm{PV}$ cells connected in series, which account for a peak power of $46.3 \mathrm{Wp}$. Therefore the total power of the glass facade is $1,343 \mathrm{Wp}$. The energy produced by the PV glass facade since its commissioning in September 16 of 2010 until December 31 of 2011 was $1,354 \mathrm{kWh}$ and the energy yield in 2011 was $1,026 \mathrm{kWh}$.

\section{H. Solar Tracker}

The first initiative to integrate renewable energy in the Campus of IPB was the installation of a typical and pioneer microgeneration PV system. It was initially installed on the ground and later, with external fund, the PV panel was installed in a two-axis solar tracker as shown in Fig. 11. This PV system is composed by:

- A string of 16 PV modules, 190GHT-2, from Kyocera, with a peak power of $3.04 \mathrm{kWp}$;

- A PV inverter, SB 3000, from SMA, to inject the energy into the grid;
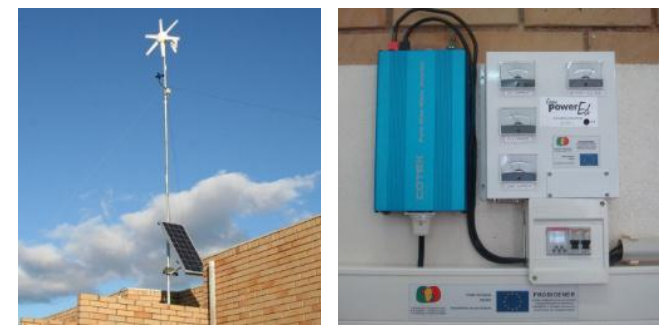

Fig. 8. Hybrid system combining solar PV and wind energy.
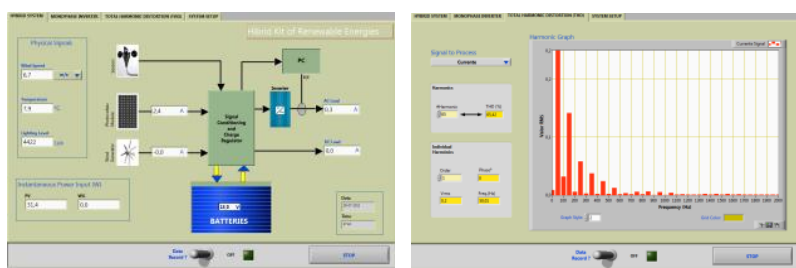

Fig. 9. User interface of the LabVIEW application developed for the hybrid system.
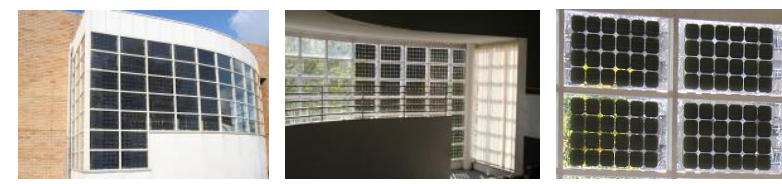

Fig. 10. Glass facade of the library of the School of Technology and Management. 

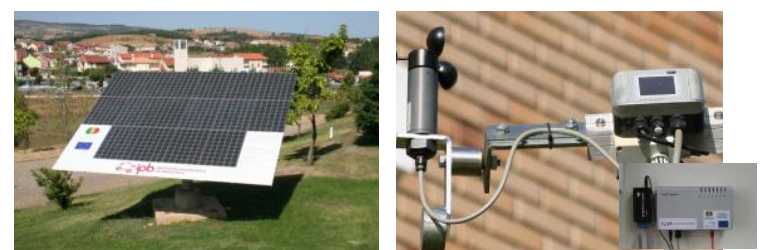

Fig. 11. Solar tracker (left) and sensors (right) for remote monitoring.

- Sensors and remote monitoring equipment for measuring the wind speed, solar radiation, temperature of modules and ambient temperature.

\section{Small Wind Turbine}

Another initiative for the integration of renewable energy in the Campus of IPB was the installation of a typical small unit of micro wind power. This WT was mounted close to the laboratory for special purposes regarding studies with a microgrid. The installed wind system consists of:

- The passaat WT, from Fortis, with $1.4 \mathrm{kWp}$;

- A rectifier with a power resister and the WB 1700 inverter from SMA;

- An anemometer and remote monitoring equipment.

\section{J. Production Unit of Biodiesel and Generator}

The VERCampus also includes a semi-automatic production unit of biodiesel from used cooking oil with a capacity of 2001 per batch (2001 per day). The unit consists of a reactor for the preparation of methoxide, a reactor to produce biodiesel, which also serves as a decanter, and a biodiesel purification unit by resins. Procedurally, the unit is fed by used cooking oil previously filtered, methanol and sodium hydroxide. After the preparation of methoxide, the biodiesel is produced by reaction between the methoxide and the used cooking oil, and then separated from glycerine by decantation, obtained as impure by-product of the reaction. Finally it is purified in the purification unit and stored for later use in the generator of the microgrid and other applications. The production unit of biodiesel and generator are shown in Fig. 13.

\section{K. Smart Microgrid}

This activity aims to implement a smart microgrid for isolated and self-sustainable systems up to $5 \mathrm{~kW}$, only
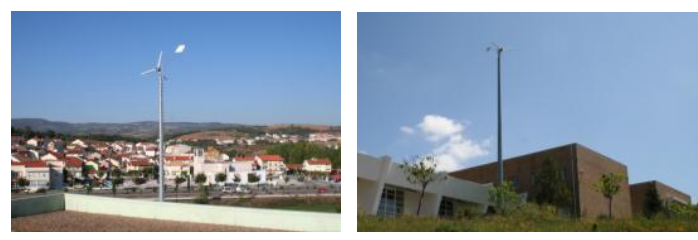

Fig. 12. Wind turbine for integration in a microgrid.
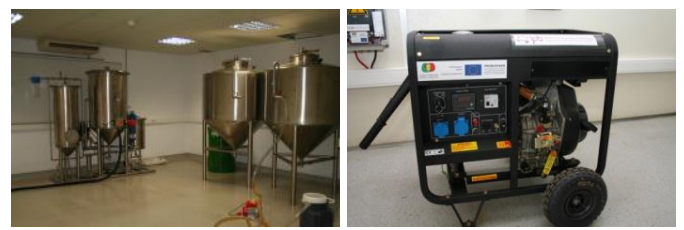

Fig. 13. Production unit of biodiesel (left) and electric generator. based on renewable energy sources with the purpose of being a demonstration platform in view of transfer of technology and applied research. The microgrid, which is illustrated in Fig. 14, can integrate several distributed power generating units, including photovoltaic, wind, hydro, fuel cells, etc., to generate electrical energy and create a grid with conventional and stable characteristics, that is, $230 \mathrm{~V}, 50 \mathrm{~Hz}$. In this case it integrates several renewable systems describe in previous sections. In a near future, the hydroelectric described in section $D$ can also be integrated. The solution is technically innovative to the electrification of houses or villages without public grid all over the World [2]. The solution can deliver a new form of conventional power generation, but based on a stand-alone, flexible and modular microgrid, and can therefore be easily expanded. The integration of a remote monitoring system of the power quality and fault diagnosis, enhanced with a set of simple procedures (manual and automatic) for decision-making makes the system extremely powerful. The bi-directional battery inverter is able to convert battery DC power into AC power and vice-versa.

The inverter is responsible for establishing a single-phase microgrid with stable voltage and frequency $(230 \mathrm{~V}$, $50 \mathrm{~Hz}$ ), thus enabling the use of conventional loads, without any difference for the users between the off-grid and the public grid. Several renewable energy sources and generators through modular units can be connected directly to the microgrid as illustrated in Fig. 14. When energy is higher than the consumption, the bi-directional inverter charges the batteries and when and the energy is not enough for the microgrid loads it provides the necessary energy from the batteries. When the power requested by users is excessive, some loads can be turned off and when consumption is low and the batteries are fully charged, the excess energy can be dissipated in heating or ventilation. The bi-directional inverter protects the battery against deep discharges and overloads guaranteeing them a longer life (more than 5 to 10 years). When the batteries are discharged, the consumption is excessive and the loads, in whole or in part, cannot be turned off, the inverter can automatically start a generator fed by biodiesel. Indeed, the off-grid system uses, with priority, renewable energy sources such as solar photovoltaic, wind, hydro or other. When necessary, or

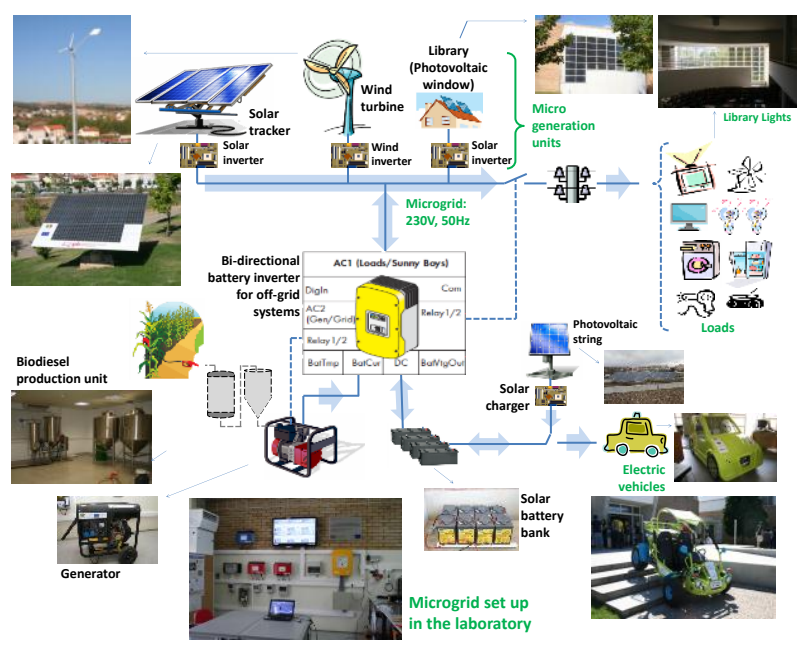

Fig. 14. Microgrid for isolated and self-sustainable systems. 
appropriate, the system uses biodiesel that is produced in the IPB biodiesel production unit described in section $J$ and there is also an on-going project that investigates the production of biodiesel from rapeseed.

The system can be easily extended by placing inverters in parallel or by creating a three-phase grid, as the electric microgrid need to be expanded. On the other hand, other microgeneration units can be connected directly to the microgrid. This possibility of expanding the grid can be used due to the characteristics of flexibility and modularity of the technology. Thus, it is possible at any time, to move from one house to the electrification of a village [2].

This activity, in context of the VERCampus Project, will certainly contribute to the widespread use of multiple renewable energy sources in microgrids which can be used, all over the World, wherever electrical energy is necessary.

\section{Integrated Monitoring System}

An integrated monitoring system based on SMA technology provides access to several data, locally or remotely trough the web, from all the renewable distributed power generation units of VERCampus, as illustrated in Fig. 15. Some of the monitored data are: daily and total energy produced, total hours of operation, voltage on DC and AC sides, instantaneous power injected into the grid, frequency, ambient temperature, PV modules temperature, solar radiation, wind speed, operating status of equipment, etc.. Some parameters of the devices can also be accessed and modified remotely on a PC using this monitoring system. The information from the sensors of temperature, solar radiation and wind speed is connected to a device called SensorBox. These data, as well as the data from the inverters are sent to an electronic unit, designated WebBox, which records all data in memory and implements a web server. Thus, it is possible to access to all this information on a PC using a browser, download the recorded data and monitor instantaneous values. Up to 50 devices can be connected to a WebBox. The communication between the WebBox and the SensorBox and inverters is made by RS-485 using a star topology.

\section{Conclusion}

This paper has presented the VERCampus Project that is being carried out in Polytechnic Institute of Bragança in order to create a "live park" of renewable energies in its

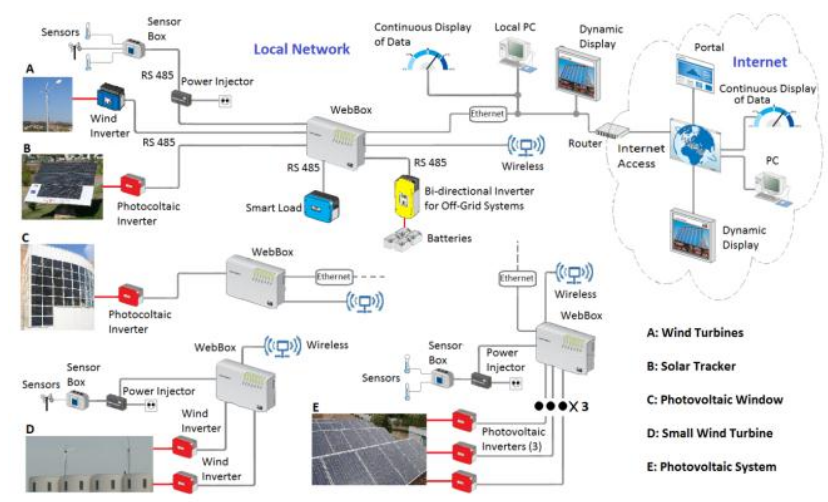

Fig. 15. Integrated monitoring system [adapted from SMA]. university Campus by means of the integration of infrastructures, technologies and new functionalities developed by students and teaching staff. Furthermore, regular initiatives are organized aimed to create an innovative green Campus as a real platform for training, education, dissemination and transfer of practical information and technology to the community. In fact, the project allows carrying out education and training activities - the main task of IPB - with a component of verification and experimental demonstration, in training and lifelong learning courses in the IPB, including master in bachelor programmes. On the other hand, the project also aims to ensure that businesses and the wider community have suitable information about the real costs of their energetic solutions and the best alternatives in order to encourage more efficient behaviour that results in a more rational use of energy. To this end, under the VERCampus Project, the IPB is also developing an action plan aimed at achieving a greater energetic sustainability through the integration of renewable energy and implementation of energy efficiency procedures, thereby contributing to the goal of reducing $\mathrm{CO}_{2}$ and get a savings of at least $20 \%$ of energy consumption by 2020 , but aimed to achieve this objective in the coming years.

\section{Acknowledgement}

The authors would like to acknowledge the financial support provided by the Portuguese Government under the "Initiative for the Investment and Employment" and the European Commission through the European Regional Development Fund, under the INTERREG Project 0128_PROBIOENER_2_E.

\section{References}

[1] F. Blaabjerg, F. Iov, T. Kerekes, R. Teodorescu, "Trends in Power Electronics and Control of Renewable Energy Systems", in Proc. of $14^{\text {th }}$ International Power Electronics and Motion Control Conference, EPE-PEMC 2010, K-1 - K-19.

[2] J. M. Guerrero, F. Blaabjerg, T. Zhelev, K. Hemmes, E. Monmasson, S. Jemei, M. P. Comech, R. Granadino, J. I. Frau, "Distributed Generation: Toward a New Energy Paradigm," IEEE Industrial Electronics Magazine, vol.4, no.1, pp.52-64, March 2010.

[3] International Hydropower Association, "Advancing Sustainable Hydropower”, 2011 Activity Report.

[4] http://www.renovaveisnahora.pt

[5] O. Paish," Small hydro power: technology and current Status", Renewable and Sustainable Energy Reviews, 2002, pp 537-556.

[6] L. Wang, D.J. Lee, J.H. Liu, Z.Z. Chen, Z.Y. Kuo, H.Y. Jang, J.J. You, J.T. Tsai, M.H. Tsai, W.T. Lin, Y.J. Lee, "Installation and Practical Operation of the First Micro Hydro Power System in Taiwan Using Irrigation Water in an Agriculture Canal", in Proc. of Power and Energy Society General Meeting - Conversion and Delivery of Electrical Energy in the $21^{\text {st }}$ Century, 20-24 July 2008, pp. 1-6

[7] M.G. Molina, M. Pacas, "Improved power conditioning system of micro-hydro power plant for distributed generation applications", in Proc. of International Conference on Industrial Technology, ICIT 2010, pp. $1733-1738$ 